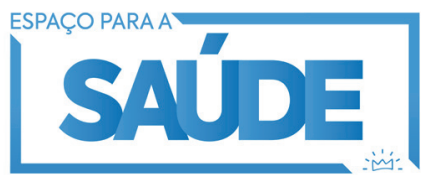

Espac. Saúde. 2021;22:e809 Doi 10.22421/1517-7130/es.2021v22.e809

ENSAIO

\title{
Promover caminhabilidade: um ensaio para a promoção de saúde e qualidade de vida de brasileiros
}

\author{
Promote walkability: an assay for the promotion of health and quality of life \\ of brazilians
}

Promover la transitabilidad: un ensayo para la promoción de la salud y la calidad de vida de los brasileños

Dartel Ferrari de Limaํㅡㄹ Lohran Anguera Lima², Adelar Aparecido Sampaio ${ }^{3}$

1 Doutor em Medicina Preventiva (FMUSP). Universidade Estadual do Oeste do Paraná. Cascavel, Paraná

2 Médico Especialista em Cirurgia da Coluna Vertebral. Santa Casa de Misericórdia de São Paulo.

São Paulo, São Paulo

3 Doutor em Educação (UFRGS). Universidade Estadual do Oeste do Paraná. Cascavel, Paraná

\section{INTRODUÇÃo}

Nós, humanos, usamos a nossa linguagem para comunicar pensamentos e ideias de maneira deliberada. Mas nossa linguagem não é perfeita e, às vezes, a intenção de nossa comunicação é turvada pelas palavras que usamos. Confusão pode resultar quando usamos uma única palavra para representar um conjunto maior de ideias. Tomemos, por exemplo, a palavra inglesa walkability traduzida para o português como caminhabilidade. Na gramática da língua portuguesa, acrescenta-se o sufixo "idade" aos adjetivos para formar substantivos que expressam a ideia de estado, condição ou situação. Desse modo,

Autor de Correspondência:

*Dartel Ferrari de Lima. E-mail: dartelferrari07@gmail.com 
a denominação dada para a condição de caminhar é caminhabilidade ${ }^{1}$.

O conceito de caminhabilidade compreende a experiência dos habitantes de uma cidade a partir de critérios como acessibilidade, possibilidade e estímulo ao deslocamento a pé pelo ambiente urbano $^{2}$. Nesse conceito, se analisa a facilidade e as barreiras que os pedestres deparam para se locomover pelas regiões da cidade. Assim, o principal objetivo da caminhabilidade é o de fazer com que as áreas urbanas sejam adequadas e compatíveis para a mobilidade dos pedestres ${ }^{3}$. Esse conceito, pela dimensão de sua importância, merece a ressalva de nuances para transmitir o conjunto de ideias que ele pretende.

Nesse sentido, esse ensaio propõe apresentar a utilidade de alguns indicadores que interferem no deslocamento urbano ativo de residentes em cidades brasileiras de maior porte. Isso oportuniza alavancar ações para que os planejadores urbanos ajam no desenvolvimento de populações mais ativas, na perspectiva de promover saúde e melhor qualidade de vida das pessoas.

A caminhabilidade representa um mecanismo que envolve a conexão de componentes multifacetários que vão além dos aspectos geográficos e físicos de uma área urbana. Parece ainda não pacificado entre urbanistas quais são os indicadores que estabelecem os índices mais fiéis de caminhabilidade para uma determinada região. No entanto, isso não impede que se destaque pontos importantes desse fenômeno, como a proximidade dos destinos, a conectividade das vias (vias interligadas, ruas sem saída), a presença de urbanização das vias (calçamento, faixas de travessia, semáforos de pedestres, placas regulamentadoras de velocidade, arborização, limpeza, calçamento plano e regular, iluminação), a sensação de segurança (violência e trânsito), o respeito e a fiscalização às leis do trânsito (controle do limite de velocidade, preferência ao pedestre, estacionamento regular) e a integração do pedestre com o transporte coletivo. Desse modo, áreas urbanas com grande concentração de pedestres podem não representar, necessariamente, espaços confortáveis, convenientes, saudáveis e sustentáveis de caminhabilidade. Essa concentração pode ser o resultado de um sistema de transporte público ineficiente ou a carência de conectividade das vias ${ }^{4}$.

Postulando-se que caminhar seja um ato desejável para a população urbana quando necessita ir de um lugar a outro, a infraestrutura física da cidade determina a rota do deslocamento, indicando onde é permitido pedestres ${ }^{5}$. Embora seja importante fornecer os meios físicos e seguros para a locomoção de pedestres, percebe-se com frequência inadequações das vias públicas. Parece dificultoso, por exemplo, idosos ou deficientes físicos enfrentarem a pé vias públicas com calçamento irregular. Desse modo, a incorporação de elementos viáveis para a mobilidade urbana deve também ter um olhar para as adversidades e para as diferenças ${ }^{6}$. Por exemplo, para adultos importa muito o deslocamento ao ponto de acesso ao transporte público para o trabalho, enquanto para crianças e adolescentes, a segurança dos espaços de entretenimento e o acesso à escola parecem prevalecer. Para idosos, poucos estudos destacam especificidades, no entanto, caminhar parece, à priori, correlacionado com a combinação de estrutura física e funções urbanas convidativas ao deslocamento ativo ${ }^{7}$.

Nessa perspectiva, o desenvolvimento de caminhabilidade não se encerra no fornecimento de vias transitáveis. A motivação de caminhar pressupõe que se tenha uma finalidade. $\mathrm{O}$ importante é a combinação sensata de destinos que forneçam diversidade de motivação para as pessoas terem a oportunidade de preencher algumas de suas necessidades. As cidades foram criadas para unir as coisas. Alguns bairros com locais atrativos têm mais pedestres do que aqueles com atrações limitadas. Desse modo, o deslocamento a pé para o trabalho 
e para a escola é um convite para a economia de dinheiro de transporte, de menor congestionamento do trânsito, de redução da poluição e do número de carros circulando, de economia de tempo, além de beneficiar a saúde da pessoa ${ }^{8}$.

Para que isso se efetive, a regra de ouro é permitir que a distância que separa o ponto de referência ao destino do pedestre não seja demasiadamente longo a ponto de inviabilizar a viagem não motorizada. Um indicativo favorável de caminhabilidade quando a distância não atende à regra de ouro, é adotar a combinação de transportes, na qual a marcha esteja incluída em algum momento 9 . Os sistemas planejados de transporte público urbano, habitualmente, separam os pontos de parada de ônibus a cada 500 metros, ou seja, uma distância percorrida em cerca de cinco minutos de caminhada ${ }^{10}$. Desse modo, conhecendo a distância entre cada ponto de parada, o usuário de ônibus pode planejar, conforme as condições do momento (disponibilidade de tempo, condições climáticas, segurança, condição física, entre outras), descer antes do destino e complementar o percurso caminhando.

O aumento do número de espaços públicos de lazer localizados próximos às moradias favorece as pessoas a caminharem. O estudo exploratório, conduzido por Cohen e colegas, envolveu 713 usuários de 8 parques públicos da cidade de Los Angeles (EUA) e 605 moradores de área até 2 milhas $(3,22 \mathrm{~km})$ de distância de cada parque e mostrou relação direta entre o nível de $\mathrm{AF}$ e o número de parques no raio de uma milha de distância das moradias ${ }^{11}$. O estudo de revisão da literatura, realizado por Lima et al. ${ }^{12}$, procurou conhecer o comportamento de acesso aos parques públicos por moradores de cidades de pequeno porte do estado do Paraná (BRA) e mostrou que $65 \%$ dos usuários acessavam os parques com deslocamento ativo quando o parque se localizava até $1,5 \mathrm{~km}$ de distância. Não escapou à observação, que $80 \%$ dos frequentadores dos parques residiam à distância não superior a $2 \mathrm{~km}$.
Em síntese, para a eficiência da caminhabilidade parece necessário uma combinação sensata de instalações físicas, lugares para ir dentro de uma proximidade razoável e disposição pessoal. Diversos estudos ${ }^{3,13,14}$ mostraram pessoas beneficiadas com o aumento da percepção positiva da saúde e da qualidade de vida por viverem em região com padrões de caminhabilidade mais desenvolvidos. Além desses benefícios práticos, há novas informações sugerindo que os negócios imobiliários estão cada vez mais interessados em empreendimentos em áreas que ofereçam maior conectividade ${ }^{3}$. Desse modo, as comunidades que estão fisicamente conectadas são compreendidas como pertencentes a uma parcela da população com maior oportunidade de ser saudável e viver com melhor qualidade de vida.

\section{A FUNCIONALIDADE DA ESTRUTURA FÍSICA PARA OS PEDESTRES}

Parece coerente supor, que a estrutura funcional do ambiente é tão relevante quanto a estrutura física. Como exemplo de funcionalidade da estrutura, a segurança percebida nas vias urbanas (trânsito e pessoal) pode incentivar o deslocamento de pedestres.

Para a segurança no trânsito, os fatores de risco são numerosos. Eles podem depender do ambiente (número de automóveis, arranjo das ruas e sinalização), dos pedestres (idade, nível de atenção e habilidade física), dos veículos em circulação (manutenção mecânica e velocidade) e políticas de segurança no trânsito (conscientização, treinamento e repressão).

Para a segurança pessoal, real ou percebida, a configuração urbana pode desempenhar um papel importante propiciando boa iluminação noturna, a diminuição de esconderijos (becos e imóveis baldios), a possibilidade de encontrar fácil ajuda, a limpeza das instalações e o policiamento ostensivo. Situações de 
insegurança urbana geram barreiras para a confiança das pessoas caminharem recreativamente ou como meio de deslocamento ativo ${ }^{15}$.

Segundo o Ministério da Saúde do Brasil, por meio do monitoramento do sistema de vigilância de doenças crônicas por inquérito telefônico (Vigitel), na edição de 2016, nas capitais dos estados brasileiros e no Distrito Federal, os hábitos de deslocamento ativo para o trabalho ou para o estudo esteve presente na rotina de $18 \%$ dos brasileiros adultos, sendo uma rotina mais prevalente em homens (20\%) do que em mulheres (16,7\%). Não escapou à atenção desse monitoramento, o deslocamento ativo de cerca de 8,5\% dos brasileiros adultos como a única forma de atividade física (AF) praticada no cotidiano ${ }^{16}$.

Ainda sobre a edição do Vigitel de 2016, caminhar recreativamente foi referido por $21,9 \%$ dos entrevistados (22,6\% de homens e $21,5 \%$ de mulheres), sendo que, $62 \%$ do conjunto da amostra caminhavam 50 minutos ou mais por dia; $94 \%$ caminhavam mais de 30 minutos por dia e $78 \%$ caminhavam três ou mais dias na semana. O impacto do caminhar como o principal condicionante da aptidão física para o brasileiro, convida para análise mais próxima do ato de caminhar. $\mathrm{O}$ volume semanal das caminhadas se alinhou adequadamente às recomendações de AF preconizadas pela Organização Mundial de Saúde (150 minutos por semana de AF moderada ou 75 minutos de AF vigorosa). Esse resultado pode indicar o caminhar como um forte elemento contributivo para margear o progresso na luta contra a inatividade física mediada pelo aprimoramento da caminhabilidade ${ }^{17}$.

\section{O ELO ENTRE AS CARACTERÍSTICAS DO AMBIENTE URBANO, A PRÁTICA DE ATIVIDADE FÍSICA E A SAÚdE}

As relações existentes entre a prática de $\mathrm{AF}$ regular e o estilo de vida ativo das pessoas estão robustamente evidenciadas na literatura, com forte associação de proteção às doenças cardiovasculares, neurodegenerativas, osteoarticulares e respiratórias, diabetes tipo 2, obesidade, cânceres (incluindo câncer de mama e o colorretal), prevenindo a mortalidade precoce por todas as causas ${ }^{18}$.

Nessa perspectiva, alguns estudos no Brasil ${ }^{19,20}$ e no exterior ${ }^{3,13,14}$ mostraram que a mobilidade urbana e a urbanização das cidades repercutem nos níveis de saúde da população. Esta observação é mais nítida nos estratos da população socioeconomicamente mais vulneráveis, ao combinar o estado de saúde a um cenário urbano menos favorecido ${ }^{21}$. Há evidências de que moradores urbanos de localidades com melhor estética, estrutura física e conectividade, tendem a ser mais ativos e mais saudáveis do que moradores de habitações suburbanas sem as mesmas condições ${ }^{22}$.

Para melhorar a saúde geral das pessoas, a OMS recomenda manter um estilo de vida ativo. No Brasil, em 2017, segundo dados do Ministério da Saúde, $43 \%$ dos brasileiros adultos estavam com atividade física insuficiente para alcançar efeitos substanciais de saúde. Ainda, no pior desse cenário, outros $14,5 \%$ da população se apresentou inativa, ou seja, não praticava nenhuma AF no tempo livre, não realizava esforços físicos relevantes no trabalho, não se deslocava ativamente para o trabalho ou para a escola e não participava da limpeza pesada de suas $\operatorname{casas}^{23}$. Essa inatividade física é, segundo a OMS, um fator de risco primário para as doenças crônicas não transmissíveis e suas complicações. Inverter esta condição de inatividade física é, portanto, o primeiro dos grandes desafios a serem perseguidos. Estabelecer interferência pública nos hábitos domiciliares e do trabalho parece ser mais complexo do que interferir nos hábitos de lazer e de deslocamento urbano ativo. Desse modo, é esperado que as ações públicas de caminhabilidade possam repercutir numa vida mais ativa das pessoas e, consequentemente, mais saudável.

O Brasil é um país fortemente marcado por desigualdades sociais e territoriais. O estado de saúde 
da população brasileira também não é uniforme. As desigualdades resultam principalmente das diferenças socioeconômicas, urbanas e ambientais dos territórios. Essas diferenças são notadas por diversos parâmetros, como a expectativa de vida da população. Para o ano de 2017, um nascido no Brasil tinha a expectativa de vida em torno de 76 anos. Enquanto no estado de Santa Catarina, a expectativa era de 79,4 anos, no Maranhão era de 70,9 anos. Entre os 26 estados da federação e o Distrito Federal, em 2017, somente oito Unidades da Federação (RJ, PR, MG, RS, SP, DF, ES e SC) apresentaram expectativa de vida ao nascer acima da média nacional. Todas essas unidades privilegiadas da federação se localizam nas regiões Sul e Sudeste ${ }^{24}$ (IBGE, 2017).

Assim, caminhabilidade e estado de saúde parecem estar também interligadas com o nível de desenvolvimento da localidade e as experiências de programas de urbanização. Esses apontamentos, mesmo que iniciais, indicam a estrada a ser percorrida ${ }^{25}$, podendo ser relevante para questionar as ações, ou a falta delas, em territórios prioritários que poderiam evoluir positivamente o "potencial de pedestre" para responder aos desafios de aumento dos hábitos ativos de vida e de saúde das pessoas.

\section{CONCLUSÃo}

Nas cidades, comportamentos urbanos reconhecidos que favorecem o exercício do caminhar com regularidade podem aumentar a adesão e a aderência de pessoas a se tornarem ou permanecerem pedestres. Isso promove descongestionamento de veículos nos centros das cidades, menor geração per capita de poluentes ambientais, economia de dinheiro das pessoas. Para esmerar ainda mais esse cenário promissor a favor dos pedestres, parece haver pouco espaço para contestar o efeito de caminhar para a promoção da saúde das pessoas e para a melhoria na qualidade de vida. Não obstante, a caminhada é a modalidade de atividade física mais prevalente na população brasileira adulta de ambos os sexos. Para muitas pessoas de maior idade, caminhar é a única atividade física possível de ser praticada. Desse modo, no âmbito mundial, se propõem estabelecer condições para estimular e aumentar o deslocamento urbano a pé.

Esse conjunto de condições foi atualizado nas últimas décadas em novos projetos urbanos e nos princípios gerais do novo urbanismo - ideia preconizada de que o ambiente físico pode ter impacto direto no oferecimento de vidas mais prósperas e felizes aos habitantes. Nessa nova forma de arranjar a cidade, a proximidade é um princípio fundamental para acessar os destinos a pé (emprego, entretenimento, compras, estudo, etc.). Nas curtas distâncias a serem percorridas, ir a pé se torna eficiente e se opõe ao modelo dominante de dependência do veículo automotor. No entanto, promover a caminhada pode ser muito mais complexo do que parece. O potencial de desenvolvimento e de soluções promotoras da caminhabilidade parece não obedecer a um único gabarito. Portanto, as ações e intervenções devem ser peculiares. Assim, a qualidade do ambiente como conforto para o pedestre, a diversidade de caminhos, a atratividade visual e a sensação de segurança são de particular importância e podem condicionar a adesão ou a desistência de ir a pé.

\section{REFERÊNCIAS}

1. Cunha C. Nova gramática do português contemporâneo. 7 ed. Rio de Janeiro, Lexikon; 2018. https://docero.com.br/ doc/1580vv

2. Yehua DW, Ei WX, Ming W, Ran W. Walkability, Land Use and Physical Activity. Sustainability. 2016;8(65):1-26. https://doi.org/10.3390/su8010065

3. Forsyth A. What is a walkable place? The walkability debate in urban design. Urban Design International. 2015;20(4): 274-292. https://doi.org/10.1057/udi.2015.22

4. Rebecchi A, Buffoli M, Dettori M, Appolloni L, Azara 
A, Castiglia P, et al. Walkable Environments and Healthy Urban Moves: Urban Context Features Assessment Framework Experienced in Milan. Sustainability. 2019;11(10):2778. https://doi.org/10.3390/su11102778

5. Lima DF, Lima LA, Silva MP. Tendências temporais dos tipos principais de exercício físico e esporte praticados no lazer na cidade de Curitiba, Brasil: 2006-2014. R. bras. Ci. e Mov. 2017;25(3):98-105. https://pesquisa.bvsalud.org/ portal/resource/pt/biblio-880745

6. Lima DF. Caminhada Teoria e Prática. 3 ed. Rio de Janeiro, Ed Sprint; 2002.

7. Yen IH, Michael YL, Perdue L. Neighborhood environment in studies of health of older adults. Am J Prev Med. 2009;37(5):455-63. https://pubmed.ncbi.nlm.nih. gov/19840702/

8. Wasfi RA, Dasgupta $\mathrm{K}$, Orpana H, Ross NA. Neighborhood walkability and body mass index trajectories: Longitudinal study of Canadians. Am J Public Health. 2016;106:934-940. https://ajph.aphapublications. org/doi/10.2105/AJPH.2016.303096

9. Kulmala R, Jääskeläinen J, Pakarinen, S. The impact of automated transport on the role, operations and costs of road operators and authorities in Finland. Finnish Transport Agency and Finnish Transport Safety Agency Helsinki. [Internet]. 2019 [citado em 10 ago 2019]. Disponível em: https:/www.traficom.fi/sites/default/files/ media/publication/EU_EIP_Impact_of_Automated Transport_Finland_Traficom_6_2019.pdf

10. Brussel M, Zuidgeest M, Pfeffer K, Van-Maarseveen M. Access or Accessibility? A Critique of the Urban Transport SDG Indicator. ISPRS Int. J. Geo-Inf. 2019;8(67):1-23. https://doi.org/doi:10.3390/ijgi8020067

11. Cohen DA, Mckenzie TL, Sehgal A, Williamson, S. Contribution of public parks to physical activity. Am J Public Health. 2007;97:509-514. https://ajph.aphapublications.org/ doi/10.2105/AJPH.2005.072447

12. Lima DF, Lima LA, Hoffmann BH, Andrelolli CRDL, Strey RE, Anguera, MG. A prática de atividade física mediada pelo meio geográfico: a distância entre as moradias e as instalações. Caderno de Educação Física e Esporte. 2020;18(1):83-88. http://dx.doi.org/10.36453/23185104.2020.v18.n1.p83

13. Shay E, Assad JK, Wali B. Walkability in the connected and automated vehicle era: A U.S. Perspective on Research Needs.First Published, Melville. 2018; 2672(35):118-128. https://doi.org/10.1177/0361198118787630

14. Edwards N, Dulai J. Examining the relationships between walkability and physical activity among older persons: what about stairs?. BMC public health. 2018;18(1):1025. https://doi.org/10.1186/s12889-018-5945-0

15. Todd M, Adams MA, Kurka J, Conway TL, Cain KL, Buman MP, et al. GIS-measured walkability, transit, and recreation environments in relation to older Adults' physical activity: A latent profile analysis. Prev Med. 2016;93:57-63. https://doi.org/10.1016/j.ypmed.2016.09.019

16. Ministério da Saúde. Secretaria de Vigilância em Saúde. Departamento de Vigilância de Doenças e Agravos não Transmissíveis e Promoção da Saúde. Vigitel Brasil 2016: vigilância de fatores de risco e proteção para doenças crônicas por inquérito telefônico. Brasília, Ministério da Saúde; 2017. https://portalarquivos2.saude.gov.br/images/ pdf/2018/marco/02/vigitel-brasil-2016.pdf

17. Lima DF, Piovani VGP, Lima LA. Recreational soccer practice among adults, in Brazilian capitals, 2011-2015. Epidemiol. Serv. Saúde. 2018;27(2):e2017284. https://doi. org/10.5123/S1679-49742018000200013

18. Lima DF, Lima LA, Luiz OC. Daily physical activity of Brazilian carriers of arterial hypertension: a transversal analysis. Colombia Médica. 2017;48(2):18-26. https:// pubmed.ncbi.nlm.nih.gov/28883668/

19. Queiroga MR, Ferreira AS, Boneti MD, Tartaruga MP, Coutinho SS, Cavazzoto TG. Caracterização do ambiente físico e prática de atividades físicas em unidades básicas de saúde de Guarapuava, Paraná, 2011-2012. Epidemiol Serv Saúde. 2016;25(4): 827-836. https://doi.org/10.5123/S167949742016000400016

20. Florindo AA, Salvador EP, Reis RS, Guimarães VV. Percepção do ambiente e prática de atividade física em adultos residentes em região de baixo nível socioeconômico. Rev Saúde Pública. 2011;45(2):302-10. https://doi.org/10.1590/S1980-65742015000400008

21. Sallis JF, Slymen DJ, Conway TL, Frank LD, Saelens BE, Cain K. Income disparities in perceived neighborhood built and social environment atributes. Health Place. 2011;17: 1274-83. https://pubmed.ncbi.nlm.nih.gov/21885324/

22. Procter-Gray E, Leveille SG, Hannan MT, Cheng J, 
Kane K, Li W. Variations in community prevalence and determinants of recreational and utilitarian walking in older age. J Aging Res. 2015;11p. doi: http://dx.doi. org $/ 10.1155 / 2015 / 382703$

23. Ministério Da Saúde. Secretaria de Vigilância em Saúde. Departamento de Vigilância de Doenças e Agravos não Transmissíveis e Promoção da Saúde. Vigitel Brasil 2017: vigilância de fatores de risco e proteção para doenças crônicas por inquérito telefônico. Brasília (DF), Ministério da Saúde; 2018. https://bvsms.saude.gov.br/bvs/publicacoes/ vigitel_brasil_2017_vigilancia_fatores_riscos.pdf

24. Instituto Brasileiro de Geografia e Estatística - IBGE. Em 2017, expectativa de vida era de 76 anos. Website. [Internet]. 2017 [citado em 12 ago 2019]. Disponível em: https://agenciadenoticias.ibge.gov.br/agencia-sala-deimprensa/2013-agencia-de-noticias/releases/23200-em2017-expectativa-de-vida-era-de-76-anos

25. Novara E. Promover os talentos para reduzir a pobreza. Estud. 2003;17(48):101-123. http://dx.doi.org/10.1590/S010340142003000200009 